\title{
O Modelo das Motivações \\ Competidoras no Domínio Funcional da Negação
}

(The Competing Motivation Model in the Functional

Domain of Negation)

\author{
Maria Angélica FuRTADo DA CUNHA \\ (Universidade Federal do Rio Grande do Norte)
}

\begin{abstract}
Brazilian Portuguese exbibits three strategies of clausal negation: the standard negative, the double negative and the postverbal negative. This paper is an attempt to describe and interpret specific linguistic properties, which supposedly derive from the use of those strategies by speakers, aiming at inferring the rules that code the discourse function of denial. The negative sentences, analyzed according to the model of competing motivations, are interpreted as the result of the conflict between iconicity and economy. The data come from Corpus Discurso \& Gramática - a língua falada e escrita na cidade do Natal.
\end{abstract}

KeY-WorDs: Negation; Competing motivations; Functionalism; Linguistic change.

Resumo: No português do Brasil co-ocorrem três estratégias de negação oracional: a negativa canônica, a negativa dupla e a negativa final. Este artigo busca descrever e interpretar propriedades lingüisticas especificas que ocorrem no uso dessas estratégias pelos falantes, com o fim de depreender as regras de codificação da função discursiva de quebra de expectativa. Utilizo-me da teoria das motivaçoes competidoras como abordagem analítica para as negativas, que são interpretadas como resultado do conflito entre iconicidade e economia. A análise tem como fonte de dados o Corpus Discurso \& Gramática - a língua falada e escrita na cidade do Natal.

PalavRas-CHAVE: Negação; Motivações competidoras; Funcionalismo; Mudança lingüistica.

D.E.L.T.A., 17:1, 2001 (1-30) 


\section{Introdução}

Neste trabalho analiso três mecanismos de negação recorrentes no português do Brasil - a negativa canônica pré-verbal, a negativa dupla e a negativa final - sob o enfoque da Lingüística Funcional, de inspiração em Givón, Hopper, Traugott, Bybee e Thompson, entre outros. Em especial, vou-me aprofundar nos conceitos mais centrais do funcionalismo: marcação, iconicidade e gramaticalização. A co-existência desses três mecanismos de negação oracional é interpretada como o resultado da atuação de pressões rivais sobre o sistema lingüístico. Admito que a competição entre motivações distintas é responsável, em princípio, pelos processos de variação e mudança que ocorrem nas línguas naturais.

O estudo das construções conhecidas como universais lingüísticos, como a negação, por exemplo, contribui para o entendimento da natureza do pensamento humano e da interação social na medida em que tais construções parecem refletir universais psicológicos e socioculturais (Slobin 1980). Nesse sentido, tento compreender as motivações de ordem comunicativa e/ou cognitiva para o uso das estratégias de negação na sincronia atual do português do Brasil.

O texto está organizado em quatro seções. Na primeira, exponho os postulados básicos do quadro teórico funcionalista no estudo da linguagem. Na segunda, discuto os mecanismos alternativos de negação oracional no português do Brasil. Na terceira, faço um breve retrospecto histórico do modelo das motivações competidoras e analiso as construções negativas como manifestação dessas motivações. A última seção sumariza as conclusões principais do trabalho.

\section{Postulados básicos da Lingüística Funcional}

As análises lingüísticas de orientação funcionalista trabalham diretamente sobre o postulado básico - a língua é uma estrutura maleável, sujeita às pressões do uso e constituída de um código não totalmente arbitrário. Orientado por Givón, Hopper, Traugott, Haiman e Thompson, entre outros, o funcionalismo representa uma tentativa de explicar a forma da língua a partir das funções que ela desempenha na interação. Admite que um grande conjunto de fenômenos lingüísticos fundamentais é o resultado da adapta- 
ção da estrutura gramatical às necessidades comunicativas dos usuários da língua. Se a função mais importante da língua é a contínua interação entre as pessoas, que se alternam como falantes e ouvintes, essa função deve, de algum modo, condicionar a forma do código lingüístico.

Partimos do princípio de que a gramática de uma língua natural é dinâmica e maleável, adaptando-se a pressões internas e externas, que continuamente interagem e se confrontam. Assim sendo, a gramática é vista como um conjunto de convenções resultantes de motivações de natureza distinta, em que sobressaem as pressões de uso. Admitimos que a gramática de qualquer língua exibe padrões morfossintáticos estáveis, sistematizados pelo uso, ao lado de mecanismos de codificação emergentes, cujos princípios motivadores buscamos descrever. Nesse sentido, o surgimento de novas estruturas morfossintáticas é motivado por fatores de natureza comunicativa e cognitiva. Tomamos, então, a sintaxe como resultado da cristalização ou regularização de estratégias discursivas recorrentes, na linha de Givón (1979), que defende que a linguagem humana evoluiu do modo pragmático para o modo sintático. Logo, a sintaxe tem sua origem no discurso, aqui tomado como o conjunto de estratégias criativas empregadas pelo falante para organizar funcionalmente seu texto para um determinado ouvinte em uma determinada situação de comunicação. Entendemos, com Givón, que a sintaxe não pode ser compreendida ou estudada sem referência tanto à sua evolução a partir do discurso quanto aos fatores comunicativos que governam seu surgimento. As regras da gramática são modificadas pelo uso (isto é, as línguas mudam) e, portanto, é necessário observar a língua como ela é falada.

Dentre os princípios centrais do funcionalismo, interessam, particularmente, marcação, iconicidade e gramaticalização. Em termos sumários, 'marcação' diz respeito à presença versus ausência de uma propriedade nos membros de um par contrastante de categorias lingüísticas. 'Iconicidade' representa a hipótese de isomorfismo funcionalmente motivado entre estruturas morfossintáticas e suas funções semânticas ou pragmáticas correspondentes. 'Gramaticalização' focaliza a emergência, ao longo do tempo, de novas estruturas morfossintáticas, a partir de precursores paratáticos, sintáticos ou lexicais. 


\subsection{Marcação}

O princípio de marcação, herdado da lingüística estrutural desenvolvida pela Escola de Praga, estabelece três critérios principais para a distinção entre categorias marcadas e categorias não-marcadas, em um contraste gramatical binário:

a) complexidade estrutural: a estrutura marcada tende a ser mais complexa (ou maior) que a estrutura não-marcada correspondente;

b) distribuição de freqüência: a estrutura marcada tende a ser menos freqüente do que a estrutura não-marcada correspondente;

c) complexidade cognitiva: a estrutura marcada tende a ser cognitivamente mais complexa do que a estrutura não-marcada correspondente. Refiro-me, aqui, a fatores como esforço mental, demanda de atenção e tempo de processamento.

Há uma tendência geral, nas línguas, para que esses três critérios de marcação coincidam. Admite-se que a correlação entre marcação estrutural, marcação cognitiva e baixa freqüência de ocorrência é o reflexo mais geral da iconicidade na gramática, dado que representa o isomorfismo entre correlatos substantivos (de natureza comunicativa e cognitiva) e correlatos formais da marcação. Assim, as categorias que são estruturalmente mais marcadas tendem também a ser substantivamente mais marcadas.

\subsection{Iconicidade}

Para o funcionalismo, a estrutura da língua reflete, de algum modo, a estrutura da experiência, isto é, a estrutura do mundo, incluindo a perspectiva imposta ao mundo pelo falante. Como a linguagem é uma faculdade humana, a suposição geral é que a estrutura lingüística revela as propriedades da conceitualização humana do mundo ou as propriedades da mente humana. Assim, em sua versão original, o princípio de iconicidade postula uma relação motivada, isomórfica, de um para um, entre forma e conteúdo (Bolinger 1975, 1977).

Estudos sobre os processos de variação e mudança, ao constatar a exis- 
tência de duas ou mais formas alternativas de dizer "a mesma coisa", levaram à reformulação dessa versão forte. Na língua que usamos diariamente, especialmente na língua escrita, existem por certo muitos casos em que não há uma relação clara, transparente, entre forma e conteúdo. Há contextos comunicativos em que a codificação morfossintática é opaca em termos da função que desempenha.

Em sua versão mais branda, o princípio de iconicidade se manifesta em três subprincípios, que se relacionam à quantidade de informação, ao grau de integração entre os constituintes da expressão e do conteúdo e à ordenação linear dos segmentos. Segundo o subprincípio da quantidade, quanto maior a quantidade de informação, maior a quantidade de forma, de tal modo que a estrutura de uma construção gramatical indica a estrutura do conceito que ela expressa. Isso significa que a complexidade de pensamento tende a refletir-se na complexidade de expressão (Slobin 1980): aquilo que é mais simples e esperado se expressa com o mecanismo morfológico e gramatical menos complexo.

O subprincípio da integração prevê que os conteúdos que estão mais próximos cognitivamente também estarão mais integrados no nível da codificação - o que está mentalmente junto, coloca-se sintaticamente junto. $\mathrm{O}$ entendimento de que a distância formal corresponde à distância conceitual tem uma longa história no funcionalismo, sendo o filósofo Condillac apontado como um precursor na utilização dessa relação, de que fizeram uso também Frei (1929), Behagel (1932), Jespersen (1949) e Bolinger (1975), entre outros.

O subprincípio da ordenação linear diz que a informação mais importante tende a ocupar o primeiro lugar da cadeia sintática, de modo que a ordem dos elementos no enunciado revela a sua ordem de importância para o falante. Uma versão preliminar desse princípio foi nomeada por Jespersen (1949) como o princípio da realidade (actuality).

Do que foi exposto, conclui-se que a língua não é um mapeamento arbitrário de idéias para enunciados: razões estritamente humanas de importância e complexidade se refletem nos traços estruturais das línguas. As estruturas sintáticas não devem ser muito diferentes, na forma e organização, das estruturas semântico-cognitivas subjacentes. Como opção teórica, o princípio da iconicidade, em sua formulação atenuada, permite uma investigação detalhada das condições que governam o uso dos recursos de 
codificação morfossintática da língua.

\subsection{Gramaticalização}

Tal como concebida aqui, a gramaticalização é um parâmetro retomado e desenvolvido no quadro da lingüística funcional americana, associado aos fenômenos de variação e mudança lingüística. Com o avanço dessa linha de pesquisa, a gramaticalização passa a ser entendida não só como a reanálise de material lexical em material gramatical, na linha de Meillet (1912), mas também como a reanálise de padrões discursivos em padrões gramaticais (Hopper \& Traugott 1993). Novos recursos gramaticais podem-se desenvolver a despeito da existência de estruturas mais antigas funcionalmente equivalentes. Como conseqüência dessa evolução contínua, pode-se atestar, numa dada língua, material gramatical em diferentes estágios de desenvolvimento. Como se vê, estou adotando uma definição mais ampla de gramaticalização como a organização de material gramatical, sobretudo morfossintático, que inclui as mudanças na ordenação dos constituintes da sentença. $\mathrm{O}$ conceito de gramaticalização representa um desafio às abordagens lingüísticas que pressupõem categorias discretas encaixadas em sistemas fixos e estáveis.

A freqüência de uso é um dos traços caracterizadores do processo de regularização lingüística. Quando uma forma ou combinação de formas passa a ocorrer no discurso com freqüência crescente, ela deixa de ser um modo "inesperado" de reforçar um ponto discursivo e começa a ser interpretada como o modo "normal" e despercebido de procedimento. A recorrência de tais expressões é um dos fatores que indica se elas são ou não consideradas pela comunidade lingüística como "gramaticais".

A gramaticalização focaliza a interdependência entre langue e parole, entre estrutura e uso, entre o categórico e o menos categórico na língua. Trata da codificação de categorias, tanto diacrônica quanto sincronicamente. Nesse sentido, o processo de gramaticalização é um tipo de mudança lingüística que afeta as categorias morfossintáticas e, portanto, a própria gramática da língua. Segundo essa abordagem, a gramática de uma língua é dinâmica, incompleta e maleável. As regularidades convivem com aspectos instáveis, não completamente determinados. 
A vertente funcionalista que adotamos é essencialmente pancrônica pois os princípios que dela decorrem podem ser aplicados tanto aos padrões fluidos do uso da língua que se observam num corte sincrônico quanto aos processos de mudança que se depreendem na trajetória diacrônica. Assim, concebemos a gramaticalização como um processo pancrônico que apresenta uma perspectiva diacrônica, já que envolve mudança, e uma perspectiva sincrônica, já que implica variação que pode ser descrita como um sistema sem referência a tempo. Uma vez que um elemento lingüístico é capaz de adquirir e reter novos sentidos e usos sem perder os antigos, seu estudo requer uma perspectiva pancrônica.

\section{Mecanismos de negação no português do Brasil}

A variedade falada do português do Brasil exibe três estratégias de negação oracional:

a) a negativa canônica pré-verbal não $+\mathrm{SV}$ :

(1) ... a nova regente ... ela não tava sabendo reger direito ... (Língua falada, $2^{\circ}$ grau, p. 278)

b) a negativa dupla não $+\mathrm{SV}+n \tilde{o} o$ :

(2) ... não vou falar agora a letra do cântico não que é muito difícil ... (Língua falada, $2^{\circ}$ grau, p. 271)

c) a negativa final $\mathrm{SV}+n \tilde{a} o$ :

(3) ... tudo eu faço ... sabe? tem isso comigo não ... (Língua falada, $2^{\circ}$ grau, p. 264)

Busco descrever e interpretar propriedades lingüísticas específicas que ocorrem no uso dessas estratégias pelos falantes, com o fim de depreender as regras de codificação da função discursiva de quebra de expectativa. Tal função possibilita a ocorrência de um processo de variação/mudança na ordenação vocabular da construção negativa. A questão central a que procuro responder é: como se explica a coexistência de diferentes mecanismos de negação no português do Brasil? A resposta a essa questão implica examinar outros dois aspectos: (i) qual é a trajetória do processo de 
gramaticalização desses mecanismos? e (ii) em que grau é icônica a relação entre forma e função, nos canais da fala e da escrita, no domínio funcional da negação?

Em particular, utilizo-me da teoria das motivações competidoras, tal como formulada em Haiman (1983, 1985), Du Bois (1985) e Givón (1995), como abordagem analítica para as negativas. A análise tem como fonte de dados o Corpus Discurso \& Gramática - a língua falada e escrita na cidade do Natal (Furtado da Cunha 1998). Desse corpus extraí 1649 orações negativas produzidas por 4 estudantes de cada um dos seguintes graus de escolaridade: $8^{\mathrm{a}}$ série do $1^{\circ}$ grau, $3^{\mathrm{a}}$ série do $2^{\circ}$ grau e universitários. Cada um deles produziu cinco textos falados e, baseados nesses, cinco textos escritos, num total de 120 textos, como se segue: narrativas de experiência pessoal, narrativas recontadas, descrições de lugar, relato de procedimento e relato de opinião (cf. Furtado da Cunha 1996).

A análise dos dados sincrônicos forneceu os resultados dispostos no quadro abaixo, que exibe a distribuição das estratégias negativas de acordo com a modalidade do texto e o grau de escolaridade do falante:

\section{Quadro 1: Distribuição dos tipos de negativa por modalidade e escolaridade}

\begin{tabular}{|l|c|c|c|c|c|c|}
\cline { 2 - 7 } \multicolumn{1}{c|}{} & Faha & \multicolumn{1}{c|}{$(\mathbf{1 4 6 5})$} & \multicolumn{1}{l|}{ Escrita } & \multicolumn{1}{c|}{$(\mathbf{1 8 4})$} \\
\hline Escolar. & não+SV & não+SV+não & SV+ não & não+SV & não+SV+não & SV+ não \\
\hline $8^{\text {a }}$ & 293 & 67 & 05 & 55 & - & - \\
\hline $3^{a}$ & 508 & 52 & 02 & 63 & - & - \\
\hline Univ. & 497 & 39 & 02 & 66 & - & - \\
\hline Total & 1298 & 158 & 09 & 184 & - & - \\
\hline
\end{tabular}

Como se pode ver no quadro 1, fala e escrita diferem com relação à ocorrência dos padrões negativos. Enquanto todas as três estratégias estão presentes na oralidade, apenas a negativa pré-verbal canônica ocorre nos textos escritos. Essa distribuição revela a trajetória de gramaticalização das negativas dupla e final, que se manifestam primeiramente no discurso falado. O registro mais formal, nesse caso, a língua escrita, evita os novos padrões. Como era de se esperar, as formas mais novas estão associadas a forças sociolingüísticas inovadoras, tais como falantes mais jovens, modalidade oral e estilo coloquial. Vale notar que mesmo a negativa canônica é muito mais freqüente na fala (1298 orações) do que na 
escrita (184 orações). As freqüências diferentes parecem estar relacionadas às condições de uso da negação. Sugerimos que a maior ocorrência da negação na comunicação oral tem a ver com o fato de que as rejeições e as negações explícitas são típicas da fala, mas não parecem plausíveis na comunicação escrita. Dadas as funções características da negação, a natureza interativa da fala explica a grande ocorrência de orações negativas nessa modalidade, comparada aos textos escritos.

Se estamos diante de uma mudança lingüística em curso, não é surpreendente encontrar algumas diferenças na ocorrência das três variantes entre falantes mais velhos e mais jovens. O quadro 2 mostra a freqüência relativa das negativas nos dados da fala de acordo com o grau de escolaridade do estudante:

\section{Quadro 2: Distribuição dos tipos de negativa na modalidade oral por escolaridade}

\begin{tabular}{|l|c|c|c|c|}
\hline Escolar. & Total & não+SV & não+SV+não & SV+não \\
\hline $8^{a}$ & 365 & $293(80.2 \%)$ & $67(18.3 \%)$ & $05(1.3 \%)$ \\
\hline $3^{a}$ & 562 & $508(90.3 \%)$ & $52(9.2 \%)$ & $02(0.3 \%)$ \\
\hline Univ. & 538 & $497(92.3 \%)$ & $39(7.2 \%)$ & $02(0.3 \%)$ \\
\hline
\end{tabular}

Note-se que, nos dados da fala, quanto mais alto o grau de escolaridade do falante, menor a ocorrência das negativas dupla e pós-verbal: é na fala dos estudantes da $8^{a}$ série, em oposição aos das séries mais avançadas, que se encontra a maior freqüência das duas construções negativas. Assim, há uma correlação entre grau de escolaridade, e conseqüentemente idade, e o uso das diferentes estratégias de negação. A ausência tanto da negativa dupla quanto da final nos textos escritos parece correlacionarse com uma influência do processo educativo no uso dos mecanismos de negação, uma vez que o ensino normativo proscreve o emprego, típico das situações mais informais ou coloquiais, de mais de uma marca de negação na mesma sentença.

A baixa freqüência de negativas pós-verbais parece estar relacionada ao instrumento de coleta de dados usado nesta pesquisa - gravação de relatos produzidos pelos falantes, com pouca tomada de turno pelo interlocutor, que apenas estimulava o falante ou mudava o assunto da entrevista. Assim, o corpus não representa conversação natural. A observação empírica do português falado revela que a negativa pós-verbal ocor- 
re, preferencialmente, como resposta a perguntas diretas. Embora o número de ocorrências para esse padrão seja pequeno e não autorize conclusões definitivas, 3 das 9 negativas finais em meus dados representam esse contexto discursivo. Veja-se o exemplo abaixo, no qual o falante explica como acompanhar, ao teclado, uma pessoa cantando:

(4) ... ou então você dá o mesmo acorde e fica lá ... passando por cima das notas ... isso aí é ... como é o nome? sei não ... (Língua falada, $8^{a}$ série, p. 377)

No que se segue, vou comentar os usos típicos das estratégias negativas na comunicação real, falada e escrita. Os relatos são indicativos de tendências gerais e não se pretendem conclusivos. Do ponto de vista de sua motivação discursiva, os três padrões negativos ocorrem em diferentes situações comunicativas (cf. Tottie 1991, Givón 1995, Thompson 1995). São usados:

1. para recusar uma oferta ou sugestão, como em (5);

2. para rejeitar uma asserção:

a) previamente mencionada (negação explícita), como em (6);

b) pressuposta (negação implícita), como em (7).

Meus dados apóiam essa classificação funcional embora haja apenas quatro casos da categoria de recusa. Vamos examinar algumas ocorrências. O fragmento abaixo ilustra o uso da negativa dupla como uma recusa a um convite explícito. O falante está contando como foi convidado a ser presidente de uma associação protestante de jovens e recusou:

(5) ... e teve uma pessoa que chegou para mim e perguntou ... "Gerson ... você aceita ficar no cargo e tudo?" num sei quê ... eu disse ... "não ... num aceito não porque ... (Língua falada, $2^{\circ}$ grau, p. 178)

Em (6), a negativa rejeita uma asserção presente no contexto imediato, exemplificando, assim, uma negação explícita. O falante está narrando o filme Uma linda mulher. A negativa dupla nega a informação dada pelo próprio falante de que o carro que seguia o personagem principal estava sendo dirigido por seu próprio motorista. Assim, essa negativa funciona como um recurso de auto-reparo: 
(6) ... e um motorista dele ... nesse tempo ele ... num era ... num era um motorista dele não ... era do hotel ... porque ele ficou sem motorista ... (Língua falada, $2^{\circ}$ grau, p. 244)

A negativa em (7) nega uma asserção implícita, algo que o falante assume que o seu interlocutor está inclinado a ouvir. Ou seja, a negativa desfaz uma expectativa “incorreta” (cf. Givón 1979). Nesse trecho, a falante conta o filme Mudança de hábito, no qual a personagem principal, uma cantora de boate que procura abrigo em um convento, se envolve com o coral da igreja:

(7) ... a nova regente ... ela não tava sabendo reger direito ... a regente do coral ... tava errando lá um monte de coisas ... né ... quando ia dar as notas pra pessoa ... não dividia o coral em vozes ... né ... soprano ... contralto ... esse negócio todo ... (Língua falada, $2^{\circ}$ grau, p. 278)

Dado nosso conhecimento do senso comum, espera-se que um regente de coral tenha conhecimentos musicais que lhe permitam desempenhar essa tarefa a contento. A negativa contradiz essa expectativa - a pressuposição de que um regente de coral saiba como reger.

Com respeito à sua motivação discursiva, então, as três construções negativas parecem se sobrepor funcionalmente. As negativas padrão, dupla e pós-verbal podem ser intercambiáveis uma vez que são usadas, prioritariamente, para rejeitar uma asserção ou, secundariamente, para recusar um convite. ${ }^{1}$ Meus próprios achados confirmam os resultados de Tottie (1991) e Thompson (1995).

Para analisar as funções discursivas da negação, observei apenas as negativas produzidas pelos estudantes do $2^{\circ}$ grau, num total de 625 orações. $\mathrm{O}$ quadro 3 mostra a distribuição das negativas segundo a função que desempenham:

\footnotetext{
${ }^{1}$ Schwegler (1991:194) afirma que "a posição do morfema negativo acrescenta informação pragmática importante ao significado básico”: a negativa padrão (a forma não-marcada) simplesmente declara um fato, sem pressuposição, enquanto as negativas dupla e pós-verbal (as formas marcadas) assinalam contradição. A análise dos meus dados não sustenta o argumento de Schwegler já que todos os três padrões negativos podem ser usados para recusar, rejeitar ou contradizer uma expectativa ou asserção prévia.
} 


\section{Quadro 3: Distribuição das negativas segundo a função discursiva}

\begin{tabular}{|c|c|c|c|}
\hline Neg. explicita & Neg. implícita & Recusa & Total \\
\hline 566 & 55 & 4 & 625 \\
\hline $90 \%$ & $9 \%$ & $1 \%$ & $100 \%$ \\
\hline
\end{tabular}

Quanto ao contexto de uso específico da negativa dupla, em meus dados essa construção é predominantemente usada em porções do discurso em que o falante interrompe o tema ou tópico central da conversação, fazendo uma digressão que corresponde a uma pausa temática (cf. Givón 1983). No exemplo (8), o falante narra o filme Cemitério maldito, que seu irmão lhe contou. O referente principal desse fragmento é representado pelos meninos em cuja casa os eventos centrais acontecem. Eles decidem visitar o cemitério. A negativa dupla ocorre como material de suporte, no qual o falante detalha a comunicação central, suspendendo o referente tópico os meninos, retomado logo após a oração negativa:

(8) ... [os meninos] ficaram muito assustado e voltaram pra casa ... conseguiram sair de lá e voltaram pra casa num sei como ... como ... num sei como foi ... meu irmão disse que também num entendeu não como ... eles conseguiram voltar em casa e contaram lá ao pai dela né ... (Língua falada, $3^{\circ}$ grau, p. 28)

Outras ocorrências de negativa dupla aparecem em trechos de discurso direto ${ }^{2}$, como o exemplo (9):

(9) ... então eu era um cara super fechado assim ... um ... num falava com ninguém ... num abria os ... num abria os olhos pra ver o mundo ... foi aí que eu fui ao a um alergista ... aí ele disse ... "ah você tem que se mudar do ambiente que vocêtá ... que passa muito ônibus ... é muito ... poluído ... mude pra um ambiente mais limpo ... porque sua rinite num tá muito boa não” ... aí mainha procurou ... passou ... seis meses ... sei lá quanto tempo ... procurando nos

\footnotetext{
${ }^{2}$ Chafe (comunicação pessoal) sugeriu que a negativa dupla pode representar um padrão mais emocional em comparação com a negativa pré-verbal, uma vez que ela tende a ocorrer em contextos de discurso direto. De acordo com esse autor (Chafe 1994:217), "sem dúvida, a motivação mais comum para o discurso direto é introduzir informação avaliativa associada a um evento discursivo anterior. (...) O discurso direto pode, assim, ser visto como um modo de expressar envolvimento" e "pode também transmitir uma instrução, um conselho, uma demonstração ou explicação." Na mesma linha, Jespersen (1962:69) refere-se ao "caráter emocional da negação repetida”.
} 
classificados um lugar que ... fosse mais propício pra ... pra tratar da minha ... alergia ... (...) aí quando a gente mudou pra cá ... todo o meu mundo sei lá parece que ... expandiu os horizontes assim ... mudei pra cá ... tenho vários amigos no colégio que mora aqui perto ... (Língua falada, $8^{a}$ série, p. 364)

Nesse trecho, o falante reproduz o conselho do seu médico, mudando o sujeito eu para você na oração com duplo não, produzindo, assim, uma interrupção na cadeia referencial. Ele faz uso desse recurso para explicar o que motivou a sua mudança de endereço e como essa mudança influenciou seu comportamento.

Os casos de duplo não em meus dados sugerem que esse padrão é favorecido em contextos que correspondem a uma pausa temática, isto é, trechos em que há uma suspensão, interrupção ou digressão da cadeia tópica principal.

Vejamos, agora, a questão da posição do morfema negativo pós-verbal. A posição mais esperada para o morfema negativo nas línguas SVO é entre o S e o V, gerando a ordem S NEG V O (cf. Dryer 1989 e Dahl 1979). A ordenação NEG V é a mais comum porque, presumivelmente, ela é a mais fácil de processar, já que o escopo do marcador negativo é, geralmente, o V. ${ }^{3}$ Nas línguas românicas, contudo, a negação é freqüentemente expressa por dois morfemas negativos simultâneos, um precedendo e o outro seguindo o verbo, a assim chamada negativa dupla. Em geral, explica-se essa tendência como sendo motivada pela carga comunicativa "pesada" do morfema negativo, que transmite uma parte importante da mensagem. Haveria, assim, uma paridade entre marcação morfológica e marcação semântica ou pragmática. Dryer (1989) argumenta que o uso da negativa dupla fornece um caminho para a mudança na posição negativa se o morfema originalmente obrigatório mais tarde se torna opcional, como está acontecendo com o ne pré-verbal do francês.

Assumindo que a variação é uma conseqüência necessária da gradualidade da mudança lingüística (Lichtenberk 1991), parece que, no caso da negação no português do Brasil, estamos diante de uma mudança lingüística em progresso. Dado que atendem à mesma pressão

\footnotetext{
${ }^{3}$ Para Jespersen (1962:5) a tendência geral de se colocar a negativa na primeira posição antes do verbo se justifica por motivos de clareza.
} 
discursiva, as negativas pré-verbal, dupla e pós-verbal estão em algum tipo de variação. Essas três formas se originaram em épocas diferentes no passado: a negativa pré-verbal é a mais antiga, seguida pela negativa dupla e finalmente pela negativa pós-verbal (cf. Jespersen 1962, Croft 1991 e Dahl 1979 sobre o ciclo da negação nas línguas).

Ao invés de admitir "ciclos recursivos" de gramaticalização no domínio funcional da negação, em que um estágio da língua substitui outro, interpreto as estruturas negativas como formas concorrentes, conforme o evidencia a freqüência textual dessas formas. Nesse domínio funcional, a negativa canônica, mais antiga, coexiste e interage com as negativas dupla e final, exemplificando o conceito de camadas de Hopper (1991).

\section{Motivações competidoras no domínio da negação}

\subsection{O modelo das motivações competidoras}

O reconhecimento da atuação de forças contraditórias sobre o sistema lingüístico tem permeado a literatura por longo tempo, embora de forma instável. Segundo Hopper \& Traugott (1993), o neogramático alemão Gabelentz (1891) foi um dos primeiros a sugerir que a gramaticalização é o resultado de duas tendências em competição, uma voltada para a facilidade de articulação do som, a outra em direção à manutenção da distinção (distinctness). A pronúncia relaxada causa mudanças sonoras que "gastam" as palavras, obscurecendo as distinções. $\mathrm{Na}$ fonologia, a hipótese de motivação entre forma e significado é contemplada, por exemplo, pelos trabalhos de Sapir, Jespersen e Köler sobre o simbolismo sonoro - a associação entre a produção de um som e o conceito a ele relacionado.

O estruturalismo clássico do início do século XX enfatiza o princípio da arbitrariedade, segundo o qual a língua é um sistema autônomo que não é afetado por fatores externos. Sob esse ponto de vista, as forças estruturadoras ou os princípios organizadores que operam em um domínio não afetam o outro, o que reflete a distinção entre lingüística interna e externa. Contudo, Saussure (1973:155) reconhece que a arbitrariedade é limitada por associações e motivações relativas e propõe uma 
tipologia das línguas ao longo da dimensão de motivação, exemplificada pelas palavras compostas transparentes (por exemplo, Latim in-imicus 'inimigo') e seu oposto, opacidade, exemplificada pela tradução francesa (ou portuguesa) 'ennemi'. Saussure se refere também à aparente correlação inversa entre a expansão léxica de uma língua e a iconicidade de sua gramática.

Ainda na primeira metade do século, Zipf (1935:29, apud Haiman 1985:167) se refere à tendência em economizar esforço: "alta freqüência é a causa de pequeno tamanho", o que significa que o que é familiar, nas línguas, recebe expressão reduzida. Para ele, a complexidade (logo, a transparência) de uma expressão lingüística varia inversamente à sua freqüência. Esse argumento tem sido continuamente repetido na literatura (cf.Jespersen 1909, Meillet 1912, Osgood 1953 e Bolinger 1977, entre outros).

Em contraposição à postura estruturalista, a questão da iconicidade volta a atrair o interesse dos lingüistas, em especial a partir da década de 60 , quando o foco da atenção recai sobre os estudos tipológicos e os universais lingüísticos. Essa área de estudos foi enfatizada sobretudo pelos crioulistas, na investigação de sistemas lingüísticos que evoluíram de uma estrutura relativamente icônica para uma estrutura mais opaca por motivos de economia. Greenberg (1966) é um dos primeiros a usar o modelo de motivações em competição para explicar a variação translingüística. Para ele, assim como para Jakobson e Benveniste, tendências estatísticas, em particular as mudanças sonoras, podem obscurecer as correlações entre padrões formais e padrões semânticos ou conceituais. Reconhece(m), porém, que há uma tendência para restaurar a correlação perdida através de diferentes processos.

Retomado e reformulado no contexto da Lingüística Funcional Americana, o princípio da iconicidade prediz que, em sua origem, a relação entre forma e conteúdo é motivada. Desse modo, a iconicidade reduz o impacto da arbitrariedade, contribuindo com uma nova perspectiva nos estudos sobre a organização morfossintática da língua e, em particular, sobre o processo de gramaticalização.

A concepção de gramática como uma estrutura emergente reconhece a interação das motivações que operam na língua. Num modelo como esse, nenhuma língua é ótima, isto é, totalmente motivada, porque os 
princípios que governam a existência dos tipos lingüísticos estão em conflito. Nesse sentido, a motivação é entendida como uma correspondência entre nossa percepção do mundo e nossa codificação dessa percepção. Historicamente as línguas se movimentam constantemente para trás e para a frente, entre os pólos de uma expressão compacta e sintética e uma expressão segmentada e analítica. Isso porque o dever de ser claro está sempre em luta com o dever de ser rápido e natural. Segundo Givón (1995), a funcionalidade plena existe apenas em algum ponto no meio do ciclo de evolução de uma forma. No final do ciclo, com a erosão fonética, a situação é de pobreza de marca, em oposição ao início, quando existia um excesso de marca.

As motivações podem ser distinguidas ao longo da dimensão de clareza referencial vs economia e também ao longo da dimensão interna vs externa. De acordo com essa orientação, a gramática de uma língua natural é concebida como um sistema que se adapta a pressões internas e externas ao sistema, que continuamente interagem e se confrontam. As mudanças lingüísticas são, em muitos casos, resultado da interação entre essas pressões. O processo de regularização das formas lingüísticas representa um aspecto interno da gramática, de acordo com o princípio estabelecido por Du Bois (1985) de que padrões discursivos recorrentes exercem pressão sobre padrões estruturais. Ou, em suas palavras, "as gramáticas codificam melhor o que os falantes fazem mais”. Para Givón (1995), que compartilha o mesmo ponto de vista, a língua é uma arena interativa, onde sub-sistemas competidores encontram seu equilíbrio dinâmico em um compromisso eclético. É o que defende também Slobin (1980), que vê a língua como um sistema comunicativo que reflete a resolução de várias pressões concorrentes. Assim, a variação lingüística não é um processo evolutivo unidirecional rumo a um estado final ideal, mas antes uma constante e dinâmica tentativa para manter o equilíbrio entre simplificação (economia) e elaboração (iconicidade).

Temos, então, o seguinte quadro: de um lado, a necessidade de ser informativo e expressivo, o que favorece a manutenção de oposições distintivas; de outro, a tendência à redução da atividade física e mental (a lei do menor esforço, de Zipf), que leva à eliminação das diferenças. Assim, a mudança lingüística é, simultaneamente, o agente tanto da iconicidade da gramática quanto da sua opacidade. A arbitrariedade, ou ausência de iconicidade entre expressão e conteúdo, surge a partir de princípios como 
economia, generalização e associação. Há um conflito constante entre iconicidade e economia de esforço. Nesse sentido, a língua reflete uma alternância contínua entre motivação, entendida como iconicidade, e arbitrariedade: a mudança sonora desgasta a motivação mas a analogia a reconstrói. Segundo Haiman (1985), as tendências de maximização da iconicidade e da economia são duas das motivações competidoras mais importantes que atuam nas línguas. A economia se opõe à iconicidade e contribui para o seu enfraquecimento. A motivação econômica destrói o paralelismo entre estrutura lingüística e estrutura externa. A tendência em economizar no comprimento ou complexidade de uma forma ou enunciado pode levar à opacidade ou arbitrariedade. Está claro que as línguas podem mudar, ao longo do tempo, na predominância de uma motivação sobre a outra. Anomalias e inconsistências lingüísticas são esperadas uma vez que se reconhece a existência de motivações em conflito. A língua está em constante fluxo por causa do equilíbrio dinâmico e, portanto, provisório, entre pressões rivais.

Minha hipótese é de que, tendo o ouvinte como meta, o falante procura maximizar a informatividade para atingir seus propósitos comunicativos. Ao mesmo tempo, da parte do falante há uma tendência em maximizar a economia, reduzindo o sinal falado no discurso rápido, o que resulta em desgaste fonológico e conseqüente desbotamento semântico. A economia se correlaciona, pois, com rotinização, perda semântica e aumento na freqüência de uso de um item ou construção. No processo de gramaticalização, as unidades lingüísticas tendem a perder progressivamente em complexidade semântica, significação pragmática, liberdade sintática e substância fonética, enquanto ganham em regularização e, portanto, em velocidade de processamento.

Rapidez, eficiência, clareza, expressividade e rotinização são exemplos de motivações rivais que dizem respeito à relação entre a língua e seus contextos de uso ou, mais especificamente, à negociação do significado entre falante e ouvinte no ato comunicativo. Tais necessidades e restrições do falante e do ouvinte configuram a forma da língua. A economia é assumida como um fenômeno de processamento. A eficiência no processamento, tanto para o falante quanto para o ouvinte, aumenta pelo encurtamento de formas mais comuns (estruturalmente nãomarcadas) e simplificação das formas menos usadas (marcação comportamental, cf. Croft 1990). A iconicidade também é uma questão 
de processamento: é mais eficiente que a língua seja paralela à estrutura da experiência. Segundo Givón (1985), uma experiência codificada é mais fácil de estocar, reter e comunicar se o código for maximamente isomórfico à experiência (princípio da meta-iconicidade). As explicações externas da abordagem funcional se baseiam na hipótese da estrutura lingüística como uma resposta adaptativa a pressões funcionais, em particular, adequação funcional e eficiência funcional.

\subsection{Iconicidade, economia e negação}

A análise das estratégias negativas revela a interação de motivações que competem pelo domínio da negação, uma na direção da restauração da iconicidade e a outra levando a uma perda da iconicidade, num movimento em direção à economia. A negativa dupla fornece evidência positiva ao princípio icônico da quantidade, segundo o qual quanto mais relevante e imprevisível for a informação, maior a quantidade de forma. Do ponto de vista psicológico, é mais fundamental afirmar um fato do que negá-lo ou desmenti-lo. A negação acrescenta complexidade cognitiva, que se reflete num aumento de complexidade gramatical ou morfológica. Primeiramente, observa-se que o marcador negativo pré-verbal passa por um processo de desgaste fonológico, que enfraquece o não tônico para num átono no discurso falado rápido ${ }^{4}$, conforme o quadro 4 :

\section{Quadro 4: Realização do ñ̃a nas negativas padrão e dupla}

\begin{tabular}{|l|ll|}
\hline \multicolumn{2}{|c|}{ Negativa padrão } & \multicolumn{2}{|c|}{ Negativa dupla } \\
\hline Não $279(55 \%)$ & não $10 \quad(19 \%)$ \\
\hline Num $229(45 \%)$ & num $42(81 \%)$ \\
\hline Total $508(100 \%)$ & Total $52(100 \%)$ \\
\hline
\end{tabular}

A negativa dupla funciona como uma dica dada pelo falante para que o ouvinte interprete corretamente o enunciado negativo, assegurando a processabilidade. Para reforçar a informação negativa, ou seja, a quebra da expectativa do ouvinte, o falante acrescenta um segundo

\footnotetext{
${ }^{4}$ Cf. Nascentes (1922) e Amaral (1920), que afirmam que o operador não é pronunciado num quando colocado antes do verbo.
} 
marcador não no fim da oração. Esse marcador pós-verbal pode ser interpretado como uma estratégia que compensa o desgaste fonológico do não pré-verbal e seu conseqüente enfraquecimento semântico, restabelecendo, assim, a iconicidade. A corrosão do marcador negativo pré-verbal pressionaria a emergência e posterior fixação do marcador final. ${ }^{5}$

A perda de distinção morfológica causada pelo desgaste fonológico é um fenômeno comum nas línguas, sobretudo em palavras monomorfêmicas (cf. Hopper 1994, Bybee 1988). Como vimos anteriormente, a rotinização no uso de uma forma lingüística pode levar à sua redução fonológica e perda do seu conteúdo semântico. Por um lado, no discurso falado rápido verifica-se uma tendência para a redução do signo. Por outro lado, quando um item (ou construção) é freqüentemente repetido, ele perde sua força expressiva. A repetição freqüente resulta, por economia, no enfraquecimento desse item, o que motiva, por sua vez, uma busca por redundância. A redundância é motivada pela necessidade de maximizar a facilidade de percepção. A redução fonológica, econômica, obscurece o signo, que, então, é repetido para garantir a compreensão. O reforço representa uma estratégia recorrente para recuperar material que se desgastou: restaurase uma forma semanticamente enfraquecida ou desbotada por meio da adição de um segundo morfema. O resultado desse processo é a emergência de uma construção que cobre muito do domínio funcional da forma antiga antes que ela sofresse redução e enfraquecimento. A nova forma tipicamente começa como uma variante usada esporadicamente, sua freqüência aumenta à medida que o tempo passa e, finalmente, ela pode vir a substituir a forma antiga. Como ressalta Hopper (1994:37), sem dúvida, o evento básico na mudança lingüística é a simples erosão de material fonológico.

É comum, em orações negativas, a reduplicação da negação, como em:

(10) ... eu num ... num sou nada contra [o vestibular] ... (Língua falada, $2^{\circ}$ grau, p. 201)

\footnotetext{
${ }^{5} \mathrm{~A}$ redução fonológica do marcador negativo não é um fenômeno restrito ao português falado em Natal (RN). Ramos (1997) analisa a variação na pronúncia não/num, argumentando a favor do estatuto clítico da negação no português do Brasil. Sua análise se baseia em uma amostra da fala de Belo Horizonte (MG). Mata (1997) investiga, sob a perspectiva da sociolingüística laboviana, a alternância das formas não e num no corpus do Projeto VALPB (Variação Lingüística no Estado da Paraíba).
} 
(11) ... porque o médico disse que ela não podia levar nenhuma pancada ... (Língua falada, $2^{\circ}$ grau, p. 223)

Da mesma forma, estou postulando que, de uma perspectiva diacrônica, o não pós-verbal é originalmente introduzido na negativa como um elemento de reforço opcional. À medida que a freqüência de ocorrência desse padrão aumenta, o marcador pós-verbal perde sua natureza enfática e se torna regular. Assim, a negativa dupla deixa de ser um modo "inesperado" de reforçar um ponto discursivo e começa a ser interpretada como o modo "normal" de procedimento. Via abdução, o falante cristaliza - ou gramaticaliza - o segundo não como parte da própria estrutura negativa. Temos, então, estágios sucessivos de reanálise para as construções negativas, em um processo contínuo de mudança na atribuição de fronteiras (cf. Hopper \& Traugott 1993). A redução fonológica do não pré-verbal tem duas conseqüências relacionadas. Primeiro, o marcador pós-verbal enfático é reanalisado como um constituinte da sentença negativa. Segundo, dado o seu enfraquecimento fonológico, o próprio marcador pré-verbal é reinterpretado como um elemento opcional, o que leva à emergência da construção SV + não. Esses estágios de reanálise estão representados em (12):

(12) $[[$ não + SV $]$ não $]>[$ não + SV + não $]>$ não $[S V+$ não $]>[S V+$ não $]$

Do ponto de vista estrutural, parte-se de uma construção morfologicamente mais pesada e fonologicamente mais longa e distinta a negativa dupla - para outra que é mais leve, mais curta e menos distinta - a negativa final. A posição do marcador negativo em relação ao SV parece, portanto, caracterizar estágios diferentes na ordenação da negativa no português do Brasil.

Uma evidência do caráter originalmente enfático do não pós-verbal é o fato de, na língua escrita, esse elemento geralmente vir separado da construção negativa por meio de vírgula. A vírgula é uma tentativa de representar a pausa da língua falada, que deixa o não fora da fronteira do $\mathrm{SV}$, conforme o primeiro estágio em (12). A pausa, nesse caso, tem uma função icônica: indica que o marcador negativo se aplica a toda a sentença, e não apenas ao V. Logo, a pausa pode ser vista como um recurso prosódico de marcar iconicamente o isolamento relativo do segundo não, isto é, a distância conceitual relativa entre o SV e o reforço negativo. A 
perda da pausa entre constituintes, como no segundo estágio em (12), é, segundo Havers (1931 apud Haiman 1985), motivada pela repetição freqüente da forma $A$ pausa $B$. Não apenas a pausa mas também nuances entonacionais e prosódicas podem-se perder pela força da rotinização.

A hipótese do isomorfismo prevê que expressões quase sinônimas, como se dá com as negativas do português, diferem no significado de algum modo. A hipótese da motivação, contudo, vai além, prevendo que a diferença em forma corresponde, de algum modo, à diferença em significado. Quanto maior a distância formal entre dois elementos, sejam o SV e o operador não, maior a distância conceitual entre as noções que eles representam. Assim, no primeiro estágio em (12), a pausa separa o SV do não final, cujo escopo é toda a sentença. No segundo estágio, esse não está dentro da fronteira do SV e, portanto, conceitualmente mais próximo. No último estágio, o não final está formalmente mais distante, em termos de número de morfemas intervenientes, do $\mathrm{V}$ e, portanto, conceitualmente mais distante também. Daí a falsa impressão inicial de uma asserção afirmativa na interação comunicativa. É só quando o enunciado está completo que o ouvinte é informado de que a asserção é negativa. No caso da negativa final, a complexidade formal - representada pela subversão da ordenação canônica do operador não - corresponde a maior complexidade cognitiva - a indicação da quebra da expectativa do ouvinte - que é adiada ou suspensa para o fim do enunciado. Estou entendendo proximidade conceitual, nesse caso, como o afetamento do $\mathrm{V}$ pelo não e a percepção de não $+\mathrm{V}$ como uma unidade, um todo. Assim, pode-se dizer que a diferença formal entre as três estruturas negativas reflete a distância conceitual entre o $\mathrm{V}$ e o marcador negativo em cada uma delas.

Note-se que há um outro padrão negativo no português em que o não pré-verbal é omitido e o único marcador negativo é o pronome nada:

(13) ... no dia que eu soube que ele tinha me colocado [chifre] ... num quis conversa ... não fiz nada ... sabe? nenhum ... um drama assim ... fui cobrar nada dele... (Língua falada, $2^{\circ}$ grau, p. 229)

(14) E: num pegou catapora não?

I: peguei nada ... (Língua falada, $2^{\circ}$ grau, p. 231) 
Casos como esses confirmam a hipótese de enfraquecimento fonológico e conseqüente eliminação do não pré-verbal. A tendência geral em reduzir o número de marcadores que expressam a mesma função gramatical explica o fato de o não pré-verbal não ser mais um marcador negativo obrigatório. A omissão desse marcador assinala uma mudança no domínio funcional da negação. A perda de marcadores é invariavelmente precedida por um estágio em que o uso desses morfemas é opcional, isto é, eles podem ou não ser usados sem diferença substancial de significado, como se dá com as três estratégias de negação. Uma vez que a mudança parece ser unidirecional, é possível prever a negativa final como o próximo estágio no desenvolvimento da negação. É de se esperar que, se o processo de enfraquecimento do não pré-verbal avança, haverá uma tendência para o aumento na freqüência de uso tanto das negativas duplas quanto das pós-verbais, com a ampliação dos seus contextos de ocorrência. Desse modo, a negativa dupla reflete um caminho plausível de mudança na ordenação da negativa no português do Brasil. Vale frisar, contudo, que não há nada determinístico com relação à gramaticalização. As mudanças não têm, necessariamente, que se completar. A hipótese de que, uma vez que uma mudança teve início, seu progresso é inexorável, não é empiricamente comprovada.

Uma última observação sobre a negativa pós-verbal se faz necessária. O princípio icônico da ordenação linear, segundo o qual quanto mais relevante a informação, tanto antes ela é codificada, parece ser cancelado aqui já que o marcador negativo é expresso no final da oração. Embora o não pós-verbal pareça, à primeira vista, sincronicamente arbitrário, ele é, contudo, diacronicamente motivado, se admitirmos que a direcionalidade da mudança nas negativas vai da negativa pré-verbal para a negativa dupla e daí para a negativa pós-verbal. A motivação da negativa final, então, está obscurecida porque foi cancelada por fatores históricos. Assim, temos uma série de mudanças, uma das quais na direção da restauração da iconicidade (negativa dupla) enquanto a outra leva a uma perda da iconicidade (negativa pós-verbal). Outro ponto diz respeito ao princípio da quantidade. Embora se registre, na literatura, uma forte tendência de a complexidade formal ser uma medida icônica da complexidade semântica, como no caso da negativa dupla, essa correspondência não é categórica. Ela pode ser enfraquecida ou atenuada, como no caso da negativa final, pela tendência à economia. No que diz respeito ao 
tamanho da construção negativa final, pode-se considerar, também, a iconicidade entre a dimensão formal de comprimento e a dimensão conceitual de familiaridade ou polidez: quanto mais polido o registro, mais longa a mensagem. A negativa final é característica de situações dialógicas informais, conforme comprovam meus dados.

Vários estudos focalizam o processo de reforço, ou de marcação redundante, na negação como um caso comum na história de muitas línguas (cf. Jespersen 1962, Schwegler 1988, Croft 1991, Dryer 1989, Ashby 1981, Payne 1985 e Hopper \& Traugott 1993, entre outros). O marcador redundante é identificado como tal pelo fato de que ele nem sempre vem expresso. Schwegler (1988) afirma que há uma "tendência psicolingüística" para o desenvolvimento de marcadores negativos enfáticos e mostra que eles surgem em contextos de contradição, isto é, em contextos emocionalmente pesados. Do ponto de vista funcional, há uma motivação econômica aqui: as línguas tendem a ter meios perifrásticos complexos para expressar noções que são semanticamente complexas. A introdução de elementos enfáticos na negação é geralmente explicada pelo fato de que os enunciados negativos quase sempre pressupõem o enunciado afirmativo correspondente no contexto, seja explícita seja implicitamente (cf. Givón 1979). A asserção negativa contrasta com a pressuposição positiva e portanto induz uma ênfase na asserção negativa. Assim, os marcadores negativos entram no sistema de negação como indicadores da rejeição enfática da expectativa explícita ou implícita do ouvinte. Via reanálise, o operador enfático original se torna mais tarde um operador regular e o marcador negativo originalmente obrigatório é omitido.

Payne (1985:224) observa que há uma forte tendência, nas línguas em geral, para enfatizar e reforçar a partícula negativa, freqüentemente pela adição de uma outra partícula em outra porção da sentença, formando um par de negativas encadeadas. $\mathrm{O}$ exemplo clássico citado é a construção negativa do francês, em que os pares ne ... pas e ne ...point circundam o verbo, como em je ne chante pas. A partícula negativa original do francês é o ne pré-verbal, que deriva do latim non. Nos textos do francês antigo, ne ocorre sem as contrapartes pas ou point, construção que ainda pode ser constatada em expressões do francês contemporâneo como je ne saurais dire. A partir do século XII, contudo, ne foi reforçado por pas, do latim passum (passo) e point, do latim punctum (ponto). Havia, ainda, uma outra partícula, mie, do latim mica (migalha), que não se manteve. Acredita-se que essas partículas originalmente eram objetos dos verbos com os quais 
estavam associadas, como por exemplo em il ne marche pas. Sua função original parece ter sido a de focalizar a atenção na própria negação, e não no verbo que estava sendo negado. Quanto à partícula pas, à medida que ela perdeu sua qualidade enfática, passou a ser usada em quase todos os contextos sintáticos, de tal modo que no francês coloquial moderno sua ocorrência é possível mesmo na presença de outros objetos do verbo. Além disso, nessa variedade do francês, a partícula pré-verbal ne é omitida, o que resulta numa construção negativa que exibe apenas a partícula pós-verbal pas, um traço incomum numa língua SVO como o francês.

De acordo com Jespersen (1962: 427), a posição pós-verbal do not do inglês é explicável de modo semelhante: a partícula original pré-verbal ne do inglês antigo foi primeiramente reforçada pela partícula pós-verbal nawibt (nothing, 'nada'), a qual, após a perda do ne, desenvolveu-se em not.

Hopper \& Traugott (1993:58) também citam o desenvolvimento da negação em francês como exemplo da interação cíclica entre reanálise, analogia (i.e., generalização) e reanálise. Esse processo se constitui das seguintes etapas: 1) negação com ne antes do verbo; 2) reforço opcional dos verbos de movimento através de pas; 3 ) reanálise de pas como uma partícula negativa do tipo ne $\mathrm{V}$ de movimento (pas); 4) extensão analógica de pas para outros tipos de verbo: $n e \mathrm{~V}$ (pas); 5) reanálise da partícula pas como um componente obrigatório de ne para a negação em geral: ne V pas; 6) substituição de ne por pas na língua falada, via dois estágios: (ne) V pas (reanálise de $n e$ como opcional) e V pas (reanálise pela perda de $n e$ ).

Para Ashby (1981), a retenção ou supressão de ne na negativa do francês moderno não é livre, e sim condicionada por fatores gramaticais, estilísticos e sociais, de tal modo que quanto mais informal o registro e quanto mais jovem o falante, maior a probabilidade de supressão do ne, o que confirma a mudança em curso. Ashby ressalta que a gramaticalização de um segundo marcador negativo é uma inovação no francês, se comparado ao latim vulgar e a outras línguas românicas, em que o operador negativo só é reforçado esporadicamente, em especial por substantivos que denotam insignificância.

É possível traçar um paralelo entre o processo de mudança da estrutura negativa do francês e o que se observa nas negativas do português. $\mathrm{Na}$ negativa dupla do português $(n \tilde{a} o+\mathrm{SV}+n \tilde{a} o)$, a negação também é 
redundantemente marcada: o segundo não vem reforçar a contra-expectativa veiculada pelo primeiro não, que se acha desgastado de substância fonética e conteúdo semântico. A questão que surge é: como a redundância se torna gramaticalizada ou obrigatória? Alguns autores (cf. Haiman 1985) admitem que a gramaticalização da redundância é parte da tendência de mudança de uma estrutura analítica para uma sintética, motivada pela necessidade de maximizar a facilidade de percepção.

Vimos que a distribuição da negativa dupla está relacionada ao grau de escolaridade do falante e à modalidade: em meus dados, esse tipo de negativa ocorre predominantemente nos textos falados dos estudantes da $8^{a}$ série (mais jovens do que os do $2^{\circ}$ e $3^{\circ}$ graus). Quanto à negativa final (não $+\mathrm{SV})$, sua ocorrência parece estar condicionada a fatores pragmáticos já que seu contexto de uso típico corresponde a respostas a perguntas diretas. Logo, tal como se dá com a supressão de ne em francês, as construções negativas emergentes no português também estão condicionadas por fatores gramaticais, pragmáticos e sociais, o que caracteriza o processo de gramaticalização. Note-se que o uso de negativas duplas se expande por todo o Brasil, enquanto as negativas finais parecem estar restritas aos falantes nordestinos e a algumas regiões de Minas Gerais e do Rio de Janeiro. ${ }^{6}$

Em francês, a gramaticalização de pas levou à supressão de ne; em português, a evolução da gramaticalização do não pós-verbal pode resultar na omissão do não pré-verbal e, conseqüentemente, no aumento da freqüência da negativa final. A diferença entre os dois processos é que, em francês, o segundo elemento do par de marcadores negativos, pas, não é um item lexical de sentido originalmente negativo, mas um substantivo que se especializou numa função gramatical, enquanto em português o segundo marcador negativo é idêntico ao marcador negativo original. Uma outra diferença é que ambos os marcadores pré e pós-verbais do português são iguais ao operador negativo absoluto não (non em francês

\footnotetext{
${ }^{6}$ Cf. trabalho de Roncarati (1996) sobre as construções negativas na fala do Ceará. Alkmim (1999) investiga, sob a abordagem variacionista, a ação dos fatores etnia e mobilidade geográfica no processo de mudança em curso das estratégias de negação. Sua análise se baseia em um corpus coletado na cidade de Mariana (MG), que atesta a existência, nessa região, das negativas préverbal, dupla e final. O exame de amostras do Corpus Discurso \& Gramática das cidades do Rio de Janeiro e Juiz de Fora (Rios de Oliveira \& Votre 1995, 1996) também revela a coocorrência, no português falado nessas cidades, dos três mecanismos de negação.
} 
e no em inglês), que ocorre no início de uma resposta negativa.

As semelhanças entre o ciclo de negação no francês e no português brasileiro sustentam a interpretação de que a negativa dupla em português representa um estágio de transição no processo de gramaticalização. Após um período de estabilidade relativa desse padrão, com a coocorrência dos dois marcadores negativos, é possível que o não que antecede o SV seja completamente omitido na fala, via reanálise, tendo com resultado a estrutura SV + não, que, por sua vez, passa a sofrer o processo de gramaticalização, a exemplo do que se deu no francês.

Schwegler (1988) aponta que, por um lado, a reestruturação dos padrões de negação é um fenômeno comum nas línguas do mundo e, por outro lado, metade dos vernáculos românicos introduziu um segundo marcador negativo antes da perda do marcador negativo original, favorecendo, assim, as construções pós-verbais em detrimento das pré-verbais.

As estratégias de negação no português do Brasil refletem algumas das características mais salientes da gramaticalização, tais como: a) sobreposição, que se refere à coexistência de várias camadas do mesmo fenômeno gramatical; b) enfraquecimento fonológico e semântico de uma forma como gatilho para a emergência de uma nova forma funcionalmente equivalente; c) processos morfossintáticos que levam à iconicidade entre forma e função e, finalmente, d) reanálise, através da qual um marcador originalmente opcional passa a ser usado como um marcador regular.

O desenvolvimento dessas estratégias envolve conflito e resolução de problema. A variação parece resultar da competição entre motivações funcionais opostas. Em termos estritamente estruturais, é impossível prever qual dessas tendências vencerá no final. O modelo das motivações competidoras também não nos permite prever a configuração futura do domínio funcional da negação no português, o que está de acordo com a nossa incapacidade factual de prever que mudanças uma língua pode sofrer ao longo de sua história.

\section{Considerações finais}

Como se viu, há dois tipos de mudança que são freqüentemente as- 
sociados à gramaticalização: a redução fonológica e o desbotamento semântico. Na negação do português os dois caminham juntos. A freqüência de ocorrência parece ser a força motivadora tanto para o desgaste fonológico quanto para o enfraquecimento semântico de uma forma. $\mathrm{O}$ ciclo de negação no português do Brasil pode ser interpretado como o resultado de um processo cujo objetivo é a solução de um problema de informatividade: a negativa dupla emerge em resposta ao objetivo do falante de reforçar uma relação que já existe mas se tornou desgastada. A redução fonológica do não pré-verbal reflete o efeito da repetição sobre o significado. A freqüência de uso da negativa pré-verbal cria um potencial para a perda de informação. A negativa dupla é, então, motivada por uma necessidade comunicativa. Esse novo recurso gramatical surge a despeito da existência da negativa padrão pré-verbal, funcionalmente equivalente. Vimos que na fala a negativa pré-verbal alterna com a negativa dupla em contextos que representam uma pausa temática. É a recorrência do padrão $n \tilde{a} o+\mathrm{SV}+n \tilde{a} o$, no discurso oral, que revela sua potencialidade para a gramaticalização e, em conseqüência, a possibilidade de mudança lingüística nos mecanismos de negação. A ausência da negativa dupla na escrita fornece evidência positiva de sua origem interacional. Nos textos escritos, o não pré-verbal não sofre redução e, portanto, não há necessidade pragmática para uma nova partícula reforçadora, típica da fala. Vale salientar que, ao utilizar argumentos como "necessidade comunicativa" e "resolução de problema de informatividade" não estou me referindo à existência de lacunas que precisam ser preenchidas, mas sim a estratégias usadas pelos interlocutores na produção e compreensão on line do fluxo do discurso. Creio que essas estratégias refletem processos cognitivos gerais, na linha de Hopper \& Traugott (1993) e Bybee (1985).

A teoria das motivações competidoras permite interpretar a ocorrência das três construções negativas como resultado do conflito entre iconicidade e economia no domínio funcional da negação no português do Brasil. A aparente arbitrariedade da negativa pós-verbal pode ser interpretada como o resultado de um conflito entre motivações icônicas e econômicas. Por um lado, dada a redução do ditongo do não pré-verbal, a pressão por clareza leva à emergência da negativa dupla, em um movimento em direção à iconicidade (maximização da informatividade); por outro, a exigência de rapidez na produção do discurso motiva o desenvolvimento da negativa pós-verbal, em um movimento contra a 
iconicidade (maximização da economia). A omissão do não pré-verbal fere a questão da relevância no sentido de que a negativa assinala contraexpectativa ou rejeição do pressuposto e, portanto, informação relevante. Em outras palavras, a posição final do marcador negativo não corresponde ao ponto de aterrissagem, na oração, da informação relevante. A perda de transparência da mensagem é compensada pelo ganho em velocidade de produção da informação. Assim, a economia discursiva supera a transparência semântica como motivação para a negativa pósverbal. Nesse caso, a iconicidade compete com a economia e a economia vence. Com respeito à presença do marcador negativo, então, a negativa dupla é icônica enquanto a negativa pós-verbal é econômica.

\section{REFERÊNCIAS Bibliográficas}

Alkmim, M. G. R. (1999) Ação de dois fatores externos no processo de mudança em negativas sentenciais no dialeto mineiro. Trabalho apresentado no II Congresso Nacional da ABRALIN, UFSC.

Amaral, A. (1920) O Dialeto Caipira. São Paulo: Casa Editora "O livro". Ashby, W. J. (1981) The loss of the negative particle 'ne' in French: a syntactic change in progress. Language 57:674-687.

Behagel, O. (1923-1932) Deutsche Syntax, vols. I-IV. Heidelberg: Carl Winter.

Bolinger, D. (1975) Aspects of Language. New York: Harcourt Brace Jovanovich.

(1977) The Form of Language. London: Longmans.

BybeE, J. (1985) Diagrammatic iconicity in stem-inflection relations. In: Haiman, J. (ed.). Iconicity in Syntax. Amsterdam: John Benjamins.

(1988) Semantic substance vs. contrast in the development of grammatical meaning. BLS Parasession of Grammaticization, 247-264.

Chafe, W. (1994) Discourse, Consciousness and Time. Chicago: The University of Chicago Press.

Croft, W. (1990) Typology and Universals. Cambridge: Cambridge University Press.

(1991) The evolution of negation. Journal of Linguistics 27:1-26.

DAHL, Ö. (1979) Typology of sentence negation. Linguistics 17:79-106.

Dryer, M. (1989) Universals of negative position. In: Moravcsik, E., J. WIRTH, \& M. Hammond (eds.) Studies in syntactic typology. Amsterdam: 
John Benjamins.

Du BoIs, J. W. (1985) Competing motivations. In: HaIMAN, J. (ed.). Iconicity in syntax. Amsterdam: John Benjamins.

Frei, H. (1929) La Grammaire des Fautes. Paris: Geuthner.

FurTADO DA CUNHA, M. A. (1996) Gramaticalização dos mecanismos de negação em Natal. In: Martelotta, M. E., S. J. Votre \& M. M. Cezario (orgs.) Gramaticalizaşão no Português do Brasil - Uma Abordagem Funcional. Rio de Janeiro: Tempo Brasileiro.

(org.) (1998) Corpus Discurso ev Gramática - a Lingua Falada e Escrita na Cidade do Natal. Natal: EDUFRN.

GabelEnTZ, G. von der (1891) Die Sprachwiissenschaft. Ibre Aufgaben, Methoden, und bisherigen Ergebnisse. Leipzig: Weigel.

Givón, T. (1979) On Understanding Grammar. New York: Academic Press. (1983) Introduction. In: GIvóN, T. (ed.). Topic Continuity in Discourse. Amsterdam: John Benjamins.

(1985) Iconicity, isomorphism and nonarbitrary coding in syntax. In: HAIMAN, J. (ed.) Iconicity in Syntax. Amsterdam: John Benjamins. (1995) Functionalism and Grammar. Amsterdam: John Benjamins.

GREenBERG, J. H. (1966) Some universals of grammar with particular reference to the order of meaningful elements. In: GreEnBERG, J. H. (ed.) Universals of Grammar. Cambridge: M.I.T. Press.

HaImAN, J. (1983) Iconic and economic motivation. Language 59:781-819. Natural Syntax (1985). Cambridge: Cambridge University Press.

HaVers, W. (1931) Handbuch der erklärenden Syntax. Heidelberg: Carl Winter.

HOPPER, P. (1991) On some principles of grammaticization. In: TraUGOTT, E. C. \& B. Heine (eds.) Approaches to Grammaticalization. Amsterdam: John Benjamins, 2 vols.

(1994) Phonogenesis. In: Pagliuca, W. (ed.) Perspectives on Grammaticalization [Current issues in linguistic theory, 109]. Amsterdam: John Benjamins.

Hopper, P. J. \& E. C. Traugott (1993) Grammaticalization. Cambridge: Cambridge University Press.

JeSPERSEn, O. (1909-1949) A Modern English Grammar on Historical Principles, vols. I-VII. London: Allen and Unwin.

(1962) Negation in English and other languages. In: Selected Writings of Otto Jespersen. London: Allen and Unwin.

LichtenBerK, F. (1991) On the gradualness of grammaticalization. In: 
Traugott, E. C. \& E. Heine (eds.) Approaches to Grammaticalization. Amsterdam: Jonh Benjamins, 2 vols.

MatA, A. C. da. (1997) A variável de negação na cidade de João Pessoa. Trabalho apresentado no I Simpósio de Estudos Lingüísticos (SNEL), UFPB.

MeILLET, A. (1912) L'évolution des formes grammaticales. In: Linguistique Générale et Linguistique Historique. Paris: Champion.

Nascentes, A. (1922) O Linguajar Carioca em 1922. Rio de Janeiro: Livraria Scientifica Brasileira.

Osgood, C. E. (1953) Method and Theory in Experimental Psychology. New York: Oxford University Press.

Payne, J. R. (1985) Negation. In: Shopen, T. (ed.) Language Typology and Syntactic Description, vol. II. Cambridge: Cambridge University Press. Ramos, J. M. (1997) A alternância "não" e "num” no Dialeto Mineiro: um caso de mudança lingüística. Trabalho apresentado no I Congresso Nacional da ABRALIN, UFAL.

Rios de oliveira, M. \& S. Votre (orgs.) (1995) Corpus Discurso \& Gramática - A Língua Falada e Escrita na Cidade do Rio de Janeiro. Rio de Janeiro: UFRJ. Mimeo.

(1996) Corpus Discurso \& Gramática - A Língua Falada e Escrita na Cidade de Juiz de Fora. Rio de Janeiro: UFRJ. Mimeo.

Roncarati, C. (1996) A negação no português falado. In: Macedo, A., C. Roncarati \& C. Mollica (orgs.) Variação e Discurso. Rio de Janeiro: Tempo Brasileiro.

SAussure, F. de (1973) Curso de Lingüística Geral. São Paulo: Cultrix.

SCHWEgler, A. (1988) Word-order changes in predicate negation strategies in Romance languages. Diachronica 2:21-58.

(1991) Predicate negation in contemporary Brazilian Portuguese a change in progress. Orbis 34:187-214.

Slobin, D. I. (1980) Psicolingüística. São Paulo: Companhia Editora Nacional.

Thompson, S. A. (1995) A discourse explanation for the cross-linguistic differences in the grammar of interrogation and negation. Santa Barbara: UCSB. Mimeo.

Totтie, G. (1991) Negation in English Speech and Writing. New York: Academic Press.

ZIPF, G. (1935) The Psychobiology of Language: An Introduction to Dynamic Philology. Cambridge: M.I.T. Press. 